\title{
Amitriptyline induced Galactorrhea: A case report
}

\author{
Arijit Mondal ${ }^{1}$, Aakanksha Malhotra' ${ }^{2}$, Sourav Bag ${ }^{3 *}$, Soumi Ghosh ${ }^{4}$ \\ ${ }^{1}$ Senior Resident, ${ }^{\mathbf{2 , 3}, \mathbf{4}}$ Junior Resident, Institute of Psychiatry- A Centre of Excellence, IPGMER \& SSKM Hospital, Kolkata, \\ West Bengal, India
}

*Corresponding Author:

Email: souravbag.iam@gmail.com

\begin{abstract}
There have been a lot of documented cases of antipsychotic drug induced galactorrhea or non-puerperal lactation and isolated case reports of selective serotonin reuptake inhibitor induced galactorrhea. Here we are reporting a case of amitriptyline, a tricyclic antidepressant induced galactorrhea and complete resolution when the drug was withdrawn. There are other literature documenting antidepressant induced galactorrhea. This literature here is to support and understand the current trends and mechanism as it is different from what we encounter with antipsychotic.
\end{abstract}

Keywords: Amitriptyline, Galactorrhea, Tricyclic antidepressant.

\section{Introduction}

Antipsychotic induced galactorrhea is a common side effect seen in day to day psychiatric practice. As time proceeded further, more and more case reports are published showing galactorrhea as a side effect of antidepressants also. There are a significant number of documented cases of such due to the use of nortriptyline, fluoxetine, sertraline, escitalopram, fluvoxamine, paroxetine, and others. ${ }^{1,2}$ But to our knowledge no significant case report suggesting amitriptyline alone as a cause of galactorrhea has not been published in the recent past. This case report is therefore to draw attention to the possibility of galactorrhea with amitriptyline, a drug that we prescribe very frequently in our day-to-day practice and to promote better judgement in the evaluation of galactorrhea in such scenario, and also as an aid for further researches.

\section{Case Report}

A 27 years old young unmarried female patient without any history of past medical or psychiatric illness, presented with complaints of dull aching, vague headache, and burning sensation over the head of mild to moderate intensity for 6 months without associated nausea, vomiting, photophobia, phonophobia, or any discharge from eye, nose or ear. There was no specific aggravating or reliving factor and no past history suggestive of head injury, recurrent sinusitis, visual disturbances, and any other stressors or comorbid illnesses. Along with that, there were complaints of other medically unexplained symptoms. Baseline routine investigations (complete blood count, sugar, urea, creatinine, thyroid profile) were done and reports were within normal limits. So a diagnosis of "undifferentiated somatoform disorder" F45.1 according to ICD-10 was made, ${ }^{3}$ and she was started with $10 \mathrm{mg}$ of amitriptyline once daily and later it was increased to $25 \mathrm{mg}$ once daily after 7 days. Improvement of target symptoms was reported within a month but the patient presented with milk secretion from the breast. There was no associated history of menstrual irregularities, sexual contact, discharge per vaginum, fever, skin rashes, visual blurring, headache, or recent chest wall surgery. The patient was not on oral contraceptive pill and there was no history suggestive of endocrinopathies in the family. Except for bilateral galactorrhea physical examination revealed nothing suggestive. Biochemical investigation revealed a serum prolactin level of $120.33 \mathrm{ng} / \mathrm{ml}$ (reference range for normally menstruating women $2.8-29.2 \mathrm{ng} / \mathrm{ml}$ ) and multidetector computed tomography (MDCT) scan of the brain suggested normal study. Since symptoms started after initiation of amitriptyline, so we stopped it and within a week there was the cessation of galactorrhea and normalization of serum prolactin level to $21.33 \mathrm{ng} / \mathrm{ml}$ after two weeks. As the patient had residual vague somatic symptoms, she was advised tablet bupropion $150 \mathrm{mg}$ daily and no adverse drug reaction was reported afterwards.

\section{Discussion}

Whereas dopamine produces a strong inhibitory effect on prolactin release, serotonin plays a stimulatory role in prolactin release by acting on postsynaptic 5hydroxytryptamine (5-HT) receptors directly in the hypothalamus or indirectly by presynaptic inhibition of tuberoinfundibular dopaminergic pathway via the 5-HT receptor., ${ }^{4,5}$ Galactorrhea or non-purulent milky discharge from the breast resulting from antidepressant therapy is hypothesized to be due to that. Before concluding iatrogenic causes of galactorrhea other possible causes such as pregnancy, breast stimulation, sexual intercourse, stress, exercise, causes related to the central nervous system (seizure, tumour, empty sella syndrome, irradiation), systemic disease, or local causes (Herpes-zoster infection, breast surgery) must be ruled out through detailed history, physical examination and necessary investigations. ${ }^{6}$

As antipsychotic induced galactorrhea is a common entity, caution is taken during antipsychotic treatment which is not so common while antidepressant therapy. However more and more emerging isolated case reports of galactorrhea due to use of antidepressant suggests otherwise. Study shows that serotonergic antidepressants (mainly with paroxetine, fluoxetine, sertraline, fluvoxamine, escitalopram) are associated with an approximately eight 
times higher risk of galactorrhea compared to other antidepressants. ${ }^{1,2}$ Cases of galactorrhea induced by nortriptyline, amoxapine, duloxetine are being reported nowadays. Earlier a case of ovarian cyst formation and lactation following treatment with amitriptyline was reported. ${ }^{7}$

In this case, the temporal relation with the onset and offset of the symptom respectively with use and withdraw of amitriptyline and no presence of all other pathological and psychological causes suggests a drug-induced etiology. Naranjo Adverse Drug Reaction (ADR) scale shows a score of seven suggesting a "probable" drug-induced ADR. ${ }^{8}$

In previously reported cases there was an underlying diagnosis of depressive or anxiety disorder where might be the changes in the hypothalamic-pituitary-gonadal axis precipitated the ADR in patients who were on the therapeutic dosage of antidepressants. ${ }^{9}$ But here in this case there are no such probable predisposing factors. In this case, there is an increase in prolactin level also with the use of a single psychotropic medication, Amitriptyline with no other concomitant drug administration that can cause galactorrhea.

\section{Conclusion}

Amitriptyline is a tricyclic antidepressant that is widely used by various professionals, not only by psychiatrists but in every field of medicine and surgery. So this case report is to ring a bell and to strengthen the results of previous case reports about the discussed side effect of Amitriptyline for being cautious about using the drug and close monitoring in females of reproductive age group.

\section{Conflict of Interest}

None.

\section{Source of Funding}

None.

\section{References}

1. Egberts AC, Meyboom RH, De Koning FH, Bakker A, Leufkens HG. Non-puerperal lactation associated with antidepressant drug use. Br J Clin Pharmacol. 1997;44(3):27781.

2. Nebhinani N. Sertraline-induced galactorrhea: case report and review of cases reported with other SSRIs. Gen Hosp Psychiatry. 2013;35(5):576.e3-5.

3. The ICD-10 Classification of Mental and Behavioural Disorders. 10th ed. Geneva: World Health Organization; 2007. $164 \mathrm{p}$.

4. Nicholas L, Dawkins K, Golden RN.

Pschoneuroendocrinology of depression: Prolactin. Psychiatr Clin North Am. 1998;21(2):341-58.

5. Mondal S, Saha I, Das S, Ganguly A, Das D, Tripathi SK. A new logical insight and putative mechanism behind fluoxetineinduced amenorrhea, hyperprolactinemia and galactorrhea in a case series. Ther Adv Psychopharmacol. 2013;3(6):322-34.

6. Peña KS, Rosenfeld JA. Evaluation and treatment of galactorrhea. Am Fam Physician. 2001;63(9):1763-70.

7. Rees WD. Lactation and ovarian cyst formation following treatment with amitriptyline. Practitioner. 1967;198(188):8358.

8. Naranjo CA, Busto U, Sellers EM, Sandor P, Ruiz I, Roberts EA, et al. A method for estimating the probability of adverse drug reactions. Clin Pharmacol Ther. 1981;30(2):239-45.

9. Kukreti P, Ali W, Jiloha RC. Rising trend of use of antidepressants induced non- puerperal lactation: A case report. J Clin Diagn Res. 2016;10(6):VD01-2.

How to cite this article: Mondal A, Malhotra A, Bag S. Amitriptyline induced Galactorrhea: A case report. Telangana J Psychiatry. 2020;6(2):183-184. 